Original Article

\title{
Radical Scavenging Activity and Quercetin Content of Muntingia calabura L. Leaves Extracted by Various Ethanol Concentration
}

\author{
Ratih Dyah Pertiwi ${ }^{1,4}$, Suwaldi ${ }^{2}$, Ronny Martien², and Erna Prawita Setyowati ${ }^{*}$ \\ ${ }^{1}$ Department of Pharmacy, Faculty of Health Sciences, Universitas Esa Unggul, Jln. Arjuna No. 9 A, Jakarta, \\ 15110 \\ 2Department of Pharmaceutics, Faculty of Pharmacy, Universitas Gadjah Mada, Sekip Utara, Yogyakarta, 55281 \\ ${ }^{3}$ Department of Pharmaceutical Biology, Faculty of Pharmacy, Universitas Gadjah Mada, Sekip \\ Utara, Yogyakarta, 55281 \\ ${ }^{4}$ Doctoral Program in Pharmaceutical Science, Faculty of Pharmacy, Universitas Gadjah Mada, Sekip Utara, \\ Yogyakarta, 55281 \\ ${ }^{*}$ Corresponding author: Erna Prawita Setyowati I Email: erna_prawita@ugm.ac.id
}

Received: 1 November 2019; Revised: 30 December 2019; Accepted: 10 January 2020; Published: 20 January 2020

Abstract: Muntingia calabura is broadly cultivated and has become a common roadside tree in Indonesia that is known as "Kersen," or cherry. The current study aimed to determine the activities of the phytochemical constituent (i.e., phenolic and flavonoid total contents) with various concentrations of ethanolic extract of $M$. calabura leaves (EEMC) to determine the best one and the in vitro antioxidant activities and quercetin content using TLC Densitometry. The extraction was carried out by maceration with various concentrations of ethanol $(96 \% \mathrm{v} / \mathrm{v} ; 70 \% \mathrm{v} / \mathrm{v}$ and $50 \% \mathrm{v} / \mathrm{v})$ to obtain the ethanolic extract of Muntingia calabura, L leaves. The determination of Quercetin was conducted by Thin Layer Chromatography (TLC) densitometry, and the total phenolic was analyzed with reagent Folin-Ciocalteu while the flavonoid content we identified by applying the colorimetric method. The antioxidant capacity was measured using the radical scavenging assay of 1,2-diphenyl-2picrylhydrazyl (DPPH). The phytochemical study showed that phenolics, saponins, tannins, and flavonoids were present in all EEMC. The extract obtained by $96 \%$ ethanol showed the highest total antioxidant activity, reducing power and DPPH (2,2-diphenyl-1-picrylhydrazyl) radical scavenging activity. The same extract also exhibited the highest flavonoid content. However, the extract obtained by $70 \%$ ethanol showed the phenolic content, and the highest quercetin content was obtained by using $50 \%$ ethanol. The result from the EEMC analysis indicated that Muntingia calabura leaf extract contains essential bioactive compounds and shows potential as a source of antioxidants in M. calabura which uses $96 \%$ ethanol solvent and has the highest quercetin content in M calabura using 50\% ethanol solvent.

Keywords: DPPH, muntingia calabura, phenolic total, antiradical activity, TLC densitometry

\section{INTRODUCTION}

Medicinal plants are resources of a therapeutic device for lighting human ailments. About $80 \%$ of people in developing countries in the world rely on traditional therapy for their primary health care, and about $85 \%$ of traditional medicine involves the extracts of plants. Using the increase in the awakening of the health danger and toxicities associated with the abuse of synthetic drugs, the 
interest in the use of plants and plant-based drugs has faced an increase around the world. However, many medicinal plants have not been researched to find out their pharmacological effects. A plant that has recently obtained therapeutic status is Muntingia calabura L [1].

M. calabura is widely conserved and therefore, has become a common roadside tree in Indonesia that is known as "Kersen,". M. calabura (Elaeocarpaceae), commonly known as cherry which contains phenol is a species in the genus Muntingia [2]. Meanwhile, in Indonesia, the use of M. calabura is still restricted, but it has been used to treat various diseases in the overseas. The roots of $M$. calabura have been consumed as an abortifacient in Malaysia and as an emmenagogue in Vietnam. In another country, Colombia, the flowers are infused and consumed as a tonic and tranquillizer. The methanol extract of M. calabura fruit has exposed potent DPPH quenching capacity [3].

Furthermore, phytochemical studies of various constituents of the plant have identified many bioactive flavonoids, sesquiterpenes, chalcones, and phenolic compounds [2]. The secondary metabolite classes present in the crude extracts of $M$. calabura, generally the flavonoid class, are known to be reliable for the plant's different bioactivities [4]. Past studies have proved flavones, flavanones, flavans, and biflavans to be the primary ingredients of this M. calabura, some of which have shown anti-platelet aggregation and cytotoxic activities [5]. However, the above research is mostly done in other countries than in Indonesia. Different sites for the growing of M. calabura plants will cause differences in the content of phenols and flavonoids. Besides, this research also aims to find the highest quercetin, phenols and flavonoids content from various variations of solvent concentration.

The current study is mainly focusing on the flavonoid and phenolic content of this plant. Flavonoids are the largest group of plant phenolics, for over half of the eight thousand naturally occurring phenolic compounds [6]. The main strength of dietary flavonoids is its antioxidant properties. Flavonoids are a group of natural antioxidants which are usually found in plants, fruits and vegetables. They are known to be the excellent scavengers of oxygen free radicals [7]. Phenolic and polyphenolic compounds comprise the main class of natural antioxidants present in plants, foods, and beverages [8]. Phytochemicals such as phenolics, carotenoids and flavonoids, have been exposed to possess functional properties such as antimicrobial and free radical scavenging activity. The phytoconstituents acts as a natural antioxidant and prevent free radical formation [9].

Flavonoids have continued beyond one hundred years and possess a broad spectrum of biological activities that might be able to influence processes which are not regulated in disease. Quercetin is a plant pigment that a potent antioxidant flavonoid and especially a flavonol. It is a flexible antioxidant known to possess protective abilities against damage tissue caused by several drug toxicities [10].

The determination of the total flavonoid and phenolic content of ethanol extracts from Muntingia calabura leaves (EEMC) with various concentrations and the examination on their potential antioxidant activities is essential to supply more scientific evidence for the research and development of the wild M. calabura tree. The main objective of this study is to find the best bioactive constituents of plant Muntingia calabura, the best quercetin content using TLC densitometry, the best antiradical activity using various concentrations of ethanol which could serve as a right candidate for the development of new antiradical agents. 


\section{MATERIAL AND METHODS}

\subsection{Plant Materials}

M. calabura was collected in May 2017 from BALITRO (The Research Institute for Spices and Medicinal Plants) in Bogor and was determined by the Research Center for Biology-Indonesian Institute of Sciences (LIPI) in Cibinong, Bogor.

\subsection{Chemical Materials}

Ethanol 96\%; 70\%; and 50\% (technical grade, C.V. Bratachem), Ascorbic acid (Sigma Aldrich), Gallic acid (Sigma Aldrich), $\mathrm{HCl} 2 \mathrm{~N}$ (technical grade, C.V. Bratachem), 2,2-Diphenyl-1Pikrilhidrazil (Sigma Aldrich), Folin Ciocalteu reagent (Merck), Mess Buffer, Methanol 20\% and 80\% (technical grade, $\mathrm{CV}$, Bratachem), and, $\mathrm{H} 2 \mathrm{SO} 4, \mathrm{Fe} \mathrm{Cl} 31 \%(\mathrm{AlCl} 3)$ 1\% (w/v in ethanol) and Sulphuric Acid (H2SO4) $10 \%$ (v/v in water).

\subsection{Extraction of M. calabura Leaves}

Dried M. calabura leaves were grounded and extracted with various concentrations of ethanol (96\%: 70\%; 50\%). The filtrate was evaporated to obtain the viscous extract [8].

\subsection{Phytochemical Analysis}

Chemical tests were carried out to the extract to screen for and identifybioactive chemical constituents in the medicinal plants, such as tannins, flavonoids, alkaloids, and saponins, using the standard procedures as described by Harborne [11] with slight modifications.

\subsection{The Determination of Total Phenolic Contents}

As suggested by Orak [12] that using gallic acid is the standard phenolic compound, the total phenolic content was determined by using the Folin-Ciocalteu reagent. Concentration was calculated using Gallic acid, as standard and the results were expressed as $\mathrm{mg}$ gallic acid equivalent/100 g wet weight. Gallic acid, in varying concentrations, were used to prepare a standard curve. This curve was used to relate the absorbance of the unknown samples to Gallic acid equivalents (GAE). Results were expressed as mg GAE in $1 \mathrm{~g}$ of dried sample (mg GAE/g). In short, $1 \mathrm{ml}$ of extract solution was mixed with $45 \mathrm{ml}$ of distilled water, then $1 \mathrm{ml}$ of Folin-Ciocalteu reagent was added, and the contents of the flask were mixed thoroughly. After three minutes, $3 \mathrm{ml}$ of $\mathrm{Na}_{2} \mathrm{CO}_{3}$ was added, and the mixture was allowed to stand for two hours. The absorbance was measured at 750-760 nm.

\subsection{The Determination of Total Flavonoid Contents}

The flavonoid total content was determined using a colorimetric method. The aluminum chloride colorimetric method was modified from the procedure suggested by Chang et al [13]. The total flavonoid content was determined using a standard curve with quercetin as the standard. Several milligrams of quercetin were dissolved in $80 \%$ ethanol and then diluted to 25, 50 and 100 $\mu \mathrm{g} / \mathrm{mL}$. The diluted standard solutions $(0.5 \mathrm{~mL})$ were separately mixed with $1.5 \mathrm{~mL}$ of $95 \%$ ethanol, $0.1 \mathrm{~mL}$ of $10 \%$ aluminum chloride, $0.1 \mathrm{~mL}$ of $1 \mathrm{M}$ potassium acetate and $2.8 \mathrm{~mL}$ of distilled water. After incubated at room temperature for $30 \mathrm{~min}$, the absorbance of the mixture was measured at 425 $\mathrm{nm}$. The quantity of $10 \%$ aluminum chloride was reversed by the same amount of distilled water in blank. Similarly, $0.5 \mathrm{~mL}$ of ethanol extracts or $15 \mathrm{~mL}$ standard flavonoid solutions $(100 \mu \mathrm{g} / \mathrm{mL})$ were reacted with aluminum chloride for the determination of flavonoid content as described above. 


\subsection{Thin Layer Chromatography Study for Quantification of Quercetin}

The standard and the sample were dissolved in ethanol and were filtered using Whatman Filter paper no. 41 before spotting on thin layer chromatography (TLC) plate. Each standard solution and samples were spotted on a 60 F254 silica gel plate and then eluted using a solvent system of chloroform, acetone, and formic acid (10:2:1) with track distance $0.50 \mathrm{~cm}$ and the migration distance was $90 \mathrm{~mm}$. Detection was done under ultraviolet at 254 and $366 \mathrm{~nm}$ [14].

\subsection{DPPH Antiradical Scavenging Assay}

Assay of the antioxidant activity of extracts was carried out by spectrophotometric methods using 1,1-diphenyl-2-picrylhydrazyl (DPPH). The control used was ascorbic acid as a positive control, EEMC was prepared with the concentration of $1000 \mu \mathrm{g} / \mathrm{ml}$, and $0.004 \%$ DPPH solution $(0,4 \mathrm{mM}$ in 10 $\mathrm{ml}$ methanol). Then, $300 \mu \mathrm{l}$ of each sample solution with a concentration of $0 ; 5 ; 10 ; 20 ;$ and $25 \mu \mathrm{g} / \mathrm{ml}$ was mixed with $900 \mu \mathrm{l}$ of DPPH solution. Positive control of ascorbic acid was prepared the same concentration $(0,5,10,20,25$ and $25 \mu \mathrm{g} / \mathrm{ml})$. Observations were made at minutes 1, 10, 20, and 30, using UV-Vis spectrophotometer at a wavelength of 500-550 nm [15].

The Radical Scavenging Activity (RSA) was calculated based on the decrease in DPPH absorption due to the addition of the test sample which is shown as follows:

$$
\operatorname{RSA}(\%)=\frac{(\operatorname{Abs} 1-\operatorname{Abs} 2)}{\operatorname{Abs} 1} \times 100 \%
$$

Where Abs 1 is absorbance value of DPPH blank and Abs 2 is absorbance value of sample.

\section{RESULTS AND DISCUSSION}

The material used in this research is Muntingia calabura leaves obtained from BALITRO (Research Agency of Spices and Medicinal Plants), Bogor. The results of determination that have been done in Center for Plant Conservation, Indonesian Institute of Sciences (LIPI), Cibinong, showed that the plants used in the research were a cherry plant (Muntingia calabura Linn.) Muntingiaceae family.

This study investigated a mixture of fresh and green M.calabura leaves. After harvested, they were washed and separated from their stems and twigs. The phytochemical constituents present in M. calabura plant extracts are shown in Table 1 . The phytochemical study uncovered the presence of alkaloids, tannins, phenols, and flavonoids. Furthermore, the preliminary phytochemical studies showed the presence of phenolics, saponins, tannins and flavonoids in the extract of Muntingia calabura.

Table 1. Phytochemical constituents analysis of Muntingia calabura

\begin{tabular}{ccccc}
\hline Identification & Simplicia & EEMC 96\% & EEMC 70\% & EEMC 50\% \\
\hline Flavonoids & + & + & + & + \\
Saponins & + & + & + & + \\
Tannins & + & + & + & + \\
Phenols & + & + & + \\
\hline
\end{tabular}

${ }^{*}(+)$ indicates the presence of the phytochemical constituent.

*(-) indicates absence of the phytochemical constituent 
The antioxidant compounds found in plants had different polarities, therefore, different solvents were used to isolate antioxidants. The antioxidant activity of the extract and the yield depended on the solvent [16]. Natural plant products are mainly divided into three major compounds including phenolic, terpenoids, and alkaloids. Accordingly, the study on preparation of plant extracts would be useful in the bioassay of the bioactive compounds. The extract's yield should depend on the polarity of solvents. Additionally, the solubility of the natural products and the solvent could also determine the yield. For example, polar solvents including methanol, acetone and ethanol are most commonly used to extract some flavonols, alkaloids, polyphenols and saponins [17].

The use of ethanol solvent with the different concentrations was intended to attract polar and non-polar chemical components in M. calabura leaves powder. The filtrate was concentrated using a rotary evaporator with a temperature of $80^{\circ} \mathrm{C}$ based on the boiling point of ethanol which is at $78^{\circ} \mathrm{C}$ [18]. The quantitative determination of phenolic compounds by using Folin-Ciocalteu ( $\mathrm{F}-\mathrm{C})$ reactive is a broad method [19]. The quantitative determination of phenolic compounds result that was measured with a maximum wavelength of $762 \mathrm{~nm}$ for all variant concentrations solvent $(96 \% \mathrm{v} / \mathrm{v} ; 70 \%$ $\mathrm{v} / \mathrm{v}$ and $50 \% \mathrm{v} / \mathrm{v}$ ) were identified.

The standard curve for gallic acid was $y=0.0110 x+0.0003\left(R^{2}=0.9992\right)$ where $y$ is the peak area (mAU) and $\mathrm{x}$ is the concentration (mg mL-1). The content of each compound was expressed as $\mathrm{mg} / 100 \mathrm{~g}$ of fresh leaves (Table 2). The total phenolic contents of all various concentration solvents of EEMC (96\% v/v; 70\% v/v and 50\% v/v) were respectively 120.36; 195.33 and 19.17 milligrams/grams gross crude extract (table 3). In contrast, the phenolic total content of EEMC $70 \%$ was higher than EEMC $96 \%$ and $50 \%$. They should depend on the polarity of solvents. Besides, the level of phenolics in plant sources depends on factors such as cultivation techniques, cultivars, growing conditions, maturation processes, and processing and storage conditions among others [20].

The basic concept of the aluminum chloride colorimetric method is that aluminum chloride forms acid stable complexes with the C-4 keto group and the C-3 or C-5 hydroxyl group of both flavones and flavonols. Furthermore, aluminum chloride forms acid labile complexes with the orthodihydroxyl groups in the A- or B-ring of flavonoids (Chang et al., 2002). The flavonoid total contents of all variant concentration solvents of EEMC ( $96 \% \mathrm{v} / \mathrm{v} ; 70 \% \mathrm{v} / \mathrm{v}$ and $50 \% \mathrm{v} / \mathrm{v})$ were respectively 3.387; 0.06942 and $0.06004 \% \mathrm{~b} / \mathrm{b}$ (Table 3). It indicated that the highest flavonoid total content was the EEMC $96 \%$.

Table 2. Linearity equations of reference ascorbic acid, quercetin and gallic acid

\begin{tabular}{cccc}
\hline Number & Samples & Linier equations & R \\
\hline 1. & Ascorbic acid & $\mathrm{y}=7.6113 \mathrm{x}-0.4239$ & 0.9989 \\
2. & Quercetin & $\mathrm{y}=0,1046 \mathrm{x}-0,0316$ & 0,9986 \\
3. & Gallic Acid & $\mathrm{y}=0,011 \mathrm{x}+0,0003$ & 0,9992 \\
\hline
\end{tabular}


Table 3. Total Flavonoids content, Total Phenolic Content and IC 50 of EEMC $96 \%$ EEMC70\% and 50\%

\begin{tabular}{cccc}
\hline Sample & Determination & Result & Unit \\
\hline EEMC 96\% & Total Flavonoids Content & 3,387 & $\%(\mathrm{w} / \mathrm{w})$ \\
& Total Phenolic Content & 120.36 & $\mathrm{mg} / \mathrm{gram}$ \\
& Antioxidant IC 50-DPPH & 14.17 & $\mu \mathrm{g} / \mathrm{ml}$ \\
& Total Flavonoids Content & 0.0700 & $\%(\mathrm{~b} / \mathrm{b})$ \\
& Total Phenolic Content & 195.33 & $\mathrm{mg} / \mathrm{gram}$ \\
& Antioxidant IC 50-DPPH & 26.58991 & $\mu \mathrm{g} / \mathrm{ml}$ \\
& Total Flavonoids Content & 0.0600 & $\%(\mathrm{w} / \mathrm{w})$ \\
& Total Phenolic Content & 19.17 & $\mathrm{mg} / \mathrm{gram}$ \\
& Antioxidant IC 50-DPPH & 15.36 & $\mu \mathrm{g} / \mathrm{ml}$ \\
\hline
\end{tabular}

The high content of phenolic and flavonoids in medicinal plants have been related to their antioxidant activities that play a role in the prevention of the development of the age-related disease, mainly caused by oxidative stress [21].

A technique of extraction from plants substantially affects the final quality of the herbal plants. Evaporator process at high temperature can destroy certain chemical compound in the extract and may adversely affect the efficacy of medicinal plants. Thereby a tool is needed to ensure the quality of the extract. Since the last decade, the chromatographic system has been known as the most important method for the determination of target and uncertain chemical compounds. A great number of TLC techniques have been developed and successfully adjusted into qualitative and quantitative antioxidants analysis.

In the thin layer chromatography experiment, the sample was adjusted to the thin layer as a band near the bottom edge of the layer. The separation in a closed chamber was fulfilled either by contacting the bottom edge of the layer with the mobile phase, which advanced through the layer by capillary forces, or by forcing the mobile phase to move through the layer at a controlled velocity by an external pressure source or centrifugal force. After that, the sample components were parted in space and their position and quantity were identified by scanning densitometry aided by the formation of easily detected derivatives by post-chromatographic [22].

Accordingly, the present study used TLC to examine the chromatographic pattern of the $M$ Calabura leaves extract and the results are shown in Figure 1-6 and Table 4. The quercetin contents of all various ethanol concentrations $(96 \% \mathrm{v} / \mathrm{v} ; 70 \% \mathrm{v} / \mathrm{v}$ and $50 \% \mathrm{v} / \mathrm{v})$ were respectively $0.79 ; 0.51 ; 2.29 \%$ (Table 4). The highest of quercetin content was EEMC $50 \%$. 


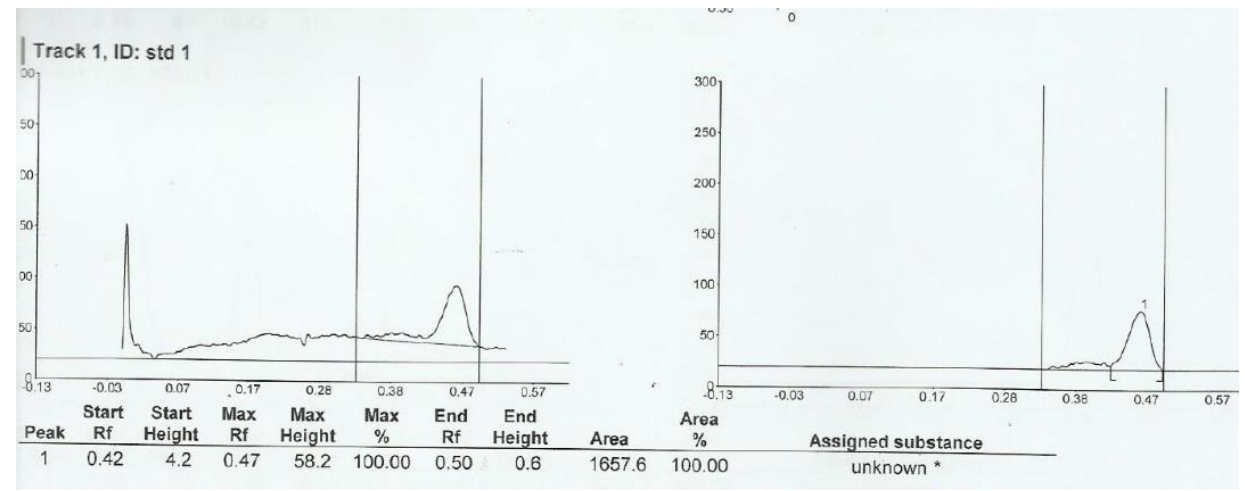

Figure 1. Thin layer chromatogram of Quercetin standard 1

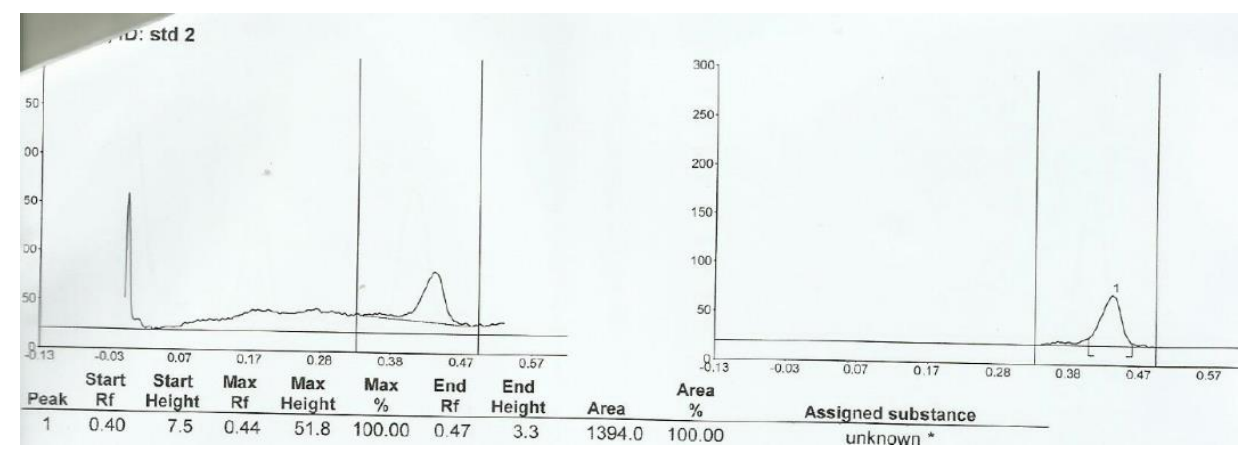

Figure 2. Thin layer chromatogram of Quercetin standard 2

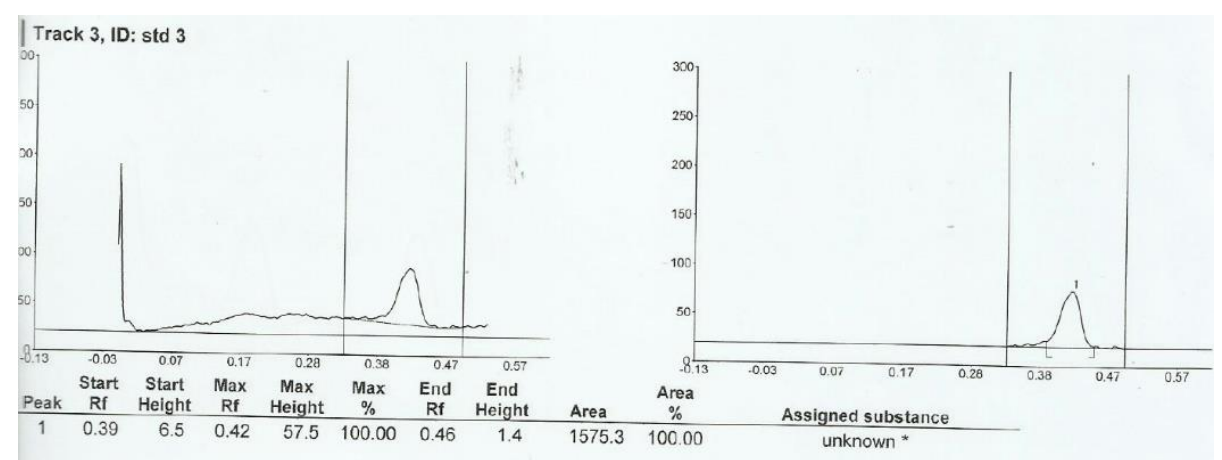

Figure 3. Thin layer chromatogram of Quercetin standard 3

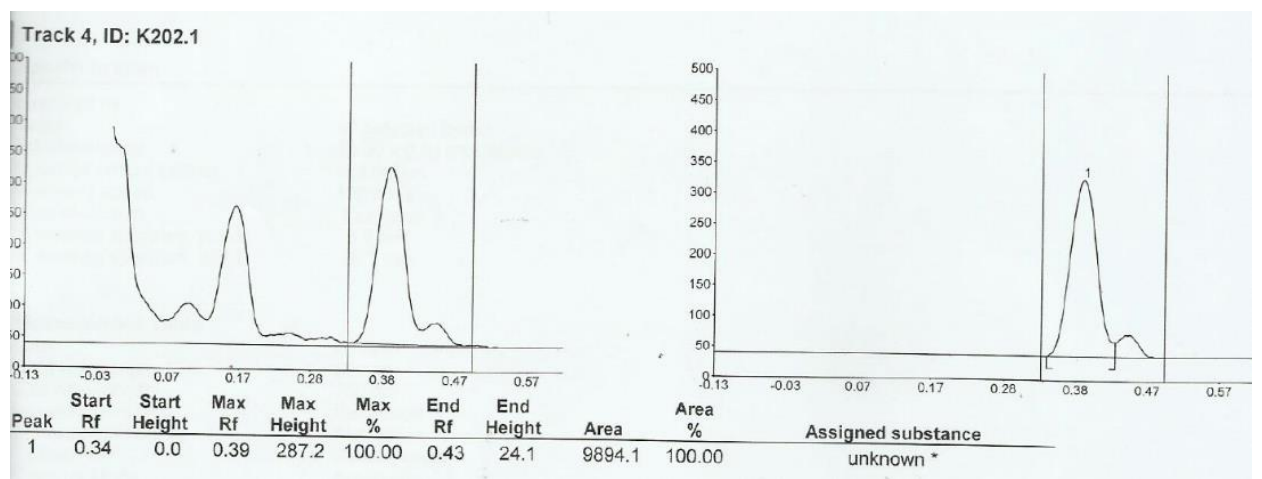

Figure 4. Thin layer chromatogram of Quercetin sample 1 (EEMC 50\%) 


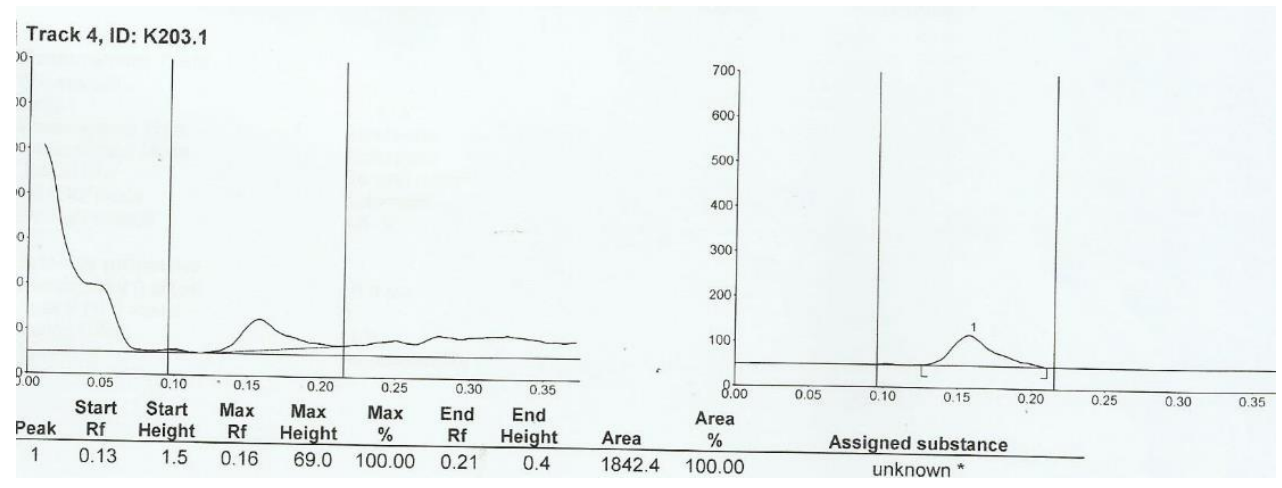

Figure 5. Thin layer chromatogram of Quercetin sample 2 (EEMC 70\%)

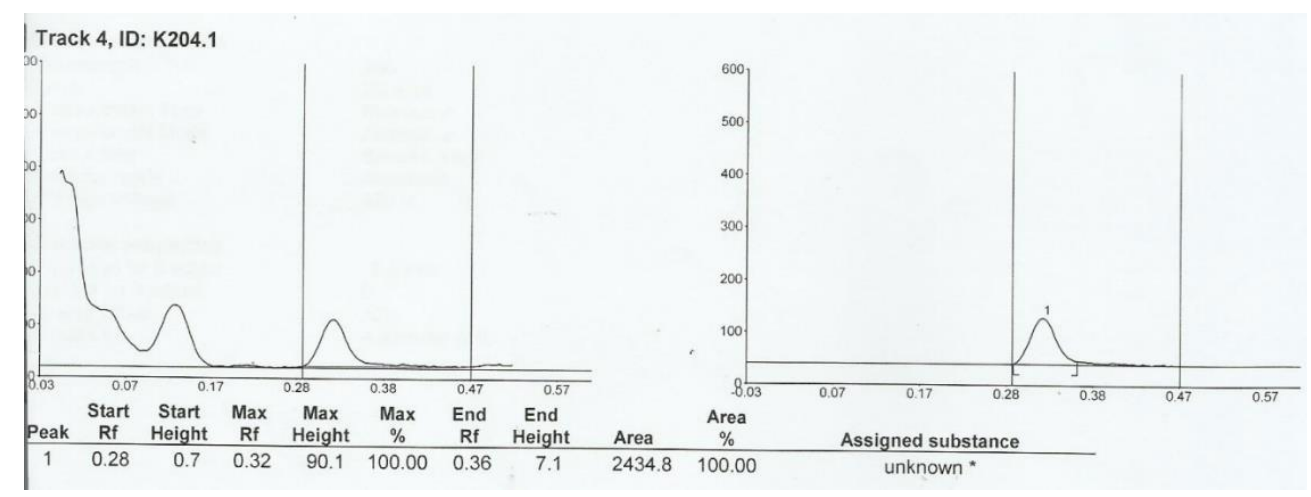

Figure 6. Thin layer chromatogram of Quercetin sample 3 ( EEMC 96\%)

Table 4. Quercetin content of EEMC 96\%, 70\% and 50\% with TLC Densitometry

\begin{tabular}{cccc}
\hline Number & Sample & Quercetin & unit \\
\hline 1. & EEMC 96\% & 0.79 & $\%$ \\
2. & EEMC 70\% & 0.51 & $\%$ \\
3. & EEMC 50\% & 2.29 & $\%$ \\
\hline
\end{tabular}

In the present study, the percentage of inhibition was measured to determine the antioxidant activity of the extracts, which was able to inhibit free radicals. DPPH assay was considered to be a more valid, more comfortable and more economical method to evaluate the radical scavenging activity of antioxidants since the radical compound was stable and needed not to be generated. DPPH is nitrogen-centered free radical having a free electron which gives a strong absorption at $517 \mathrm{~nm}$. Purple DPPH changed to yellow when its odd electron paired with the radical scavenger to reduce the DPPH-H. The decrease in the absorbance of DPPH free radical at $517 \mathrm{~nm}$ was because of the radical scavenger donated hydrogen [23]. Linearity equations and $\mathrm{IC}_{50}$ of reference ascorbic acid and EEMC are shown in Table 5. 
Table 5. Linearity equations and $\mathrm{IC}_{50}$ of reference ascorbic acid and EEMC

\begin{tabular}{ccccc}
\hline Number & Samples & Linier equations & $\mathbf{R}$ & $\begin{array}{c}\mathbf{I C}_{50} \\
(\boldsymbol{\mu g} / \mathbf{m L})\end{array}$ \\
\hline 1. & Ascorbic acid & $\mathrm{y}=19,539 \mathrm{x}+0,0682$ & 0,998 & 2,5554 \\
2. & EEMC 96\% & $\mathrm{y}=1,9125+3,9006$ & 0,9854 & 14,1700 \\
3. & EEMC 70\% & $\mathrm{y}=1.0422 \mathrm{x}+22.288$ & 0,9941 & 26.58991 \\
4. & EEMC 50\% & $\mathrm{y}=2.5689 \mathrm{x}+10.85$ & 0.9885 & 15.361 \\
\hline
\end{tabular}

The result of the antioxidant activity test that was measured with a maximum wavelength of $524 \mathrm{~nm}$ for all variant concentration solvents $(96 \% \mathrm{v} / \mathrm{v} ; 70 \% \mathrm{v} / \mathrm{v}$ and $50 \% \mathrm{v} / \mathrm{v}$ ) obtained average IC 50 value of $14.17000 ; 26.5899 ; 15.360 \mu \mathrm{g} / \mathrm{mL}$ respectively, while the result of an antioxidant activity test on ascorbic acid as a comparative standard showed an average IC 50 value of $2.5554 \mu \mathrm{g} / \mathrm{mL}$. EEMC $96 \%$ showed a better IC 50 value compared to $50 \%$ ethanol and $70 \%$. It indicated that various concentrations of solvent were influential in the antioxidant assay. The extract of $M$. calabura leaves proved that $M$. calabura contains important bioactive compounds and has the potential to be a source of antioxidant, especially the EEMC $96 \%$.

\section{CONCLUSION}

Muntingia calabura leaf extract contains essential bioactive compounds and shows potential as a source of antioxidants in M. calabura which uses $96 \%$ ethanol solvent and has the highest quercetin content in M. calabura using 50\% ethanol.

Acknowledgement : The authors thanked for the Ministry of Research Technology and Higher Education and also Excellence Scholarships Indonesian Lecturers (BUDI-DN) from Indonesia Endowment Fund for Education (LPDP).

\section{References}

1. Mahmood, N.D.; Nasir, N.L.M.; Rofiee, M.S.; Tohid, S.F.M.; Ching, S.M.; Teh, L.K.; Salleh, M.Z.; Zakaria, Z.A. Muntingia calabura: A review of its traditional uses, chemical properties, and pharmacological observations. Pharm. Biol. 2014, 52, 1598-1623.

2. Shih, C.D.; Chen, J.J.; Lee, H.H. Activation of nitric oxide signaling pathway mediates hypotensive effect of Muntingia calabura L.(Tiliaceae) leaf extract. Am. J. Chin. Med. 2006, 34, 857872.

3. Preethi, K.; Vijayalakshmi, N.; Shamna, R.; Sasikumar, J.M. In vitro antioxidant activity of extracts from fruits of Muntingia calabura Linn. from India. Pharmacogn. J. 2010, 2, 11-18.

4. Buhian, W.P.C.; Rubio, R.O.; Valle, D.L.; Martin-Puzon, J.J. Bioactive metabolite profiles and antimicrobial activity of ethanolic extracts from Muntingia calabura L. leaves and stems. Asian Pac. J. Trop. Biomed. 2016, 6, 682-685.

5. Kuo, W.L.; Liao, H.R.; Chen, J.J. Biflavans, flavonoids, and a dihydrochalcone from the stem wood of Muntingia calabura and their inhibitory activities on neutrophil pro-inflammatory responses. Molecules, 2014, 19, 20521-20535. 
6. Harborne, J.; Baxter, H.; Moss, G.P. Phytochemical Dictionary: Handbook of Bioactive Compounds from Plants, 2nd ed.; Taylor \& Francis: London, 1999.

7. Acker, S.A.B.E.; Tromp, M.N.J.L.; Haenen, G.R.M.M.; Van der Vijgh, W.J.F.; Bast, A. Flavonoids as scavengers of nitric oxide radical. Biochem. Biophys. Res. Commun. 1995, 214, 755-759.

8. Lee, E.J.; Nomura, N.; Patil, B.S.; Yoo, K.S. Measurement of total phenolic content in wine using an automatic Folin-Ciocalteu assay method. Int. J. Food Sci. Technol. 2014, 49, 2364-2372.

9. Asirvatam, R.; Christina, A.J.M. Free radical scavenging potential of Drosera indica L in presence of Dalton Ascites lymphoma (DAL) tumor bearing mice. Indones. J. Pharm. 2018, 29, 127.

10. David, A.V.A.; Arulmoli, R.; Parasuraman, S. Overviews of biological importance of quercetin: A bioactive flavonoid. Pharmacogn. Rev. 2016, 10, 84.

11. Harborne, J. Phytochemical Methods: A Guide to Modern Techniques of Plant Analysis, second. ed.; Chapman and Hall: London, 1984.

12. Orak, H.H. Total antioxidant activities, phenolics, anthocyanins, polyphenoloxidase activities in red grape varieties. Electron. J. Pol. Agric. Univ. Food Sci. Technol. 2006, 9, 117-118.

13. Chang, C.C.; Yang, M.H.; Wen, H.M.; Chern, J.C. Estimation of total flavonoid content in propolis by two complementary colorimetric methods. J. Food Drug Anal. 2002, 10, 178-182.

14. Tambunan, A.P.; Bahtiar, A.; Tjandrawinata, R.R. Influence of extraction parameters on the yield, phytochemical, TLC-densitometric quantification of quercetin, and LC-MS profile, and how to standardize different batches for long term from Ageratum conyoides L. leaves. Pharmacogn. J. 2017, 9, 767-774.

15. Andrianto, D. Biochemical Utilization of Indonesian Forest Biomass as Antioxidant, Antidiabetic, and Antihyperlipidemic Agents. Doctoral Thesis, Ehime University, Japan, 15 September 2015.

16. Aksoy, L.; Kolay, E.; Ağılönü, Y.; Aslan, Z.; Karg1oğlu, M. Free radical scavenging activity, total phenolic content, total antioxidant status, and total oxidant status of endemic Thermopsis turcica. Saudi J. Biol. Sci. 2013, 20, 235-239.

17. Jadid, N.; Hidayati, D.; Hartanti, S.R.; Arraniry, B.A.; Rachman, R.Y.; Wikanta, W. Antioxidant activities of different solvent extracts of Piper retrofractum Vahl. using DPPH assay. Presented at the PROCEEDING OF INTERNATIONAL BIOLOGY CONFERENCE 2016: Biodiversity and Biotechnology for Human Welfare, Surabaya, Indonesia, 2017, 020019.

18. Rowe, R.; Sheskey P.J.; Quinn, M.E. Handbook of Pharmaceutical Exipients, Sixth Edition.; Pharmaceutical Press and American Pharmaceutical Association: Washington USA, 2009.

19. Cicco, N.; Lanorte, M.T.; Paraggio, M.; Viggiano, M.; Lattanzio, V. A reproducible, rapid and inexpensive Folin-Ciocalteu micro-method in determining phenolics of plant methanol extracts. Microchem. J. 2009, 91, 107-110.

20. Naczk, M.; Shahidi, F. Phenolics in cereals, fruits and vegetables: Occurrence, extraction and analysis. J. Pharm. Biomed. Anal. 2006, 41, 1523-1542.

21. Azwanida, N.N. A Review on the extraction methods use in medicinal plants, principle, strength and limitation. Med. Aromat. Plants. 2015, 04, 1.

22. Moffat, A.C.; Osselton, M.D.; Widdop, B.; Watts, J. Clarke's Analysis of Drugs and Poisons: in Pharmaceuticals, Body Fluids and Postmortem Material, Fourth edition.; Pharmaceutical Press: London, Chicago, 2011. 
23. Surana, A.R.; Wagh, R.D. Estimation of total phenolic, total flavonoid content and evaluation of anti-inflammatory and antioxidant activity of Ixora coccinea Linn. stems. Indones. J. Pharm. 2017, $28,99$.

(C) 2020 by the authors. Submitted for possible open access publication under the terms and conditions of the Creative Commons Attribution (CC BY) license (http://creativecommons.org/licenses/by/4.0/). 